$\Rightarrow$ CARBON EMISSIONS

\section{COVID-19 carbon cuts}

Strict government policies have been put in place to limit the spread of COVID-19. In many nations, population confinement has been used as one such measure, resulting in drastically modified energy use owing to, for example, shifts in transportation patterns or industrial operations. Anthropogenic $\mathrm{CO}_{2}$ emissions can therefore also be expected to have changed during the pandemic.

Corinne Le Quéré from the University of East Anglia, UK, and

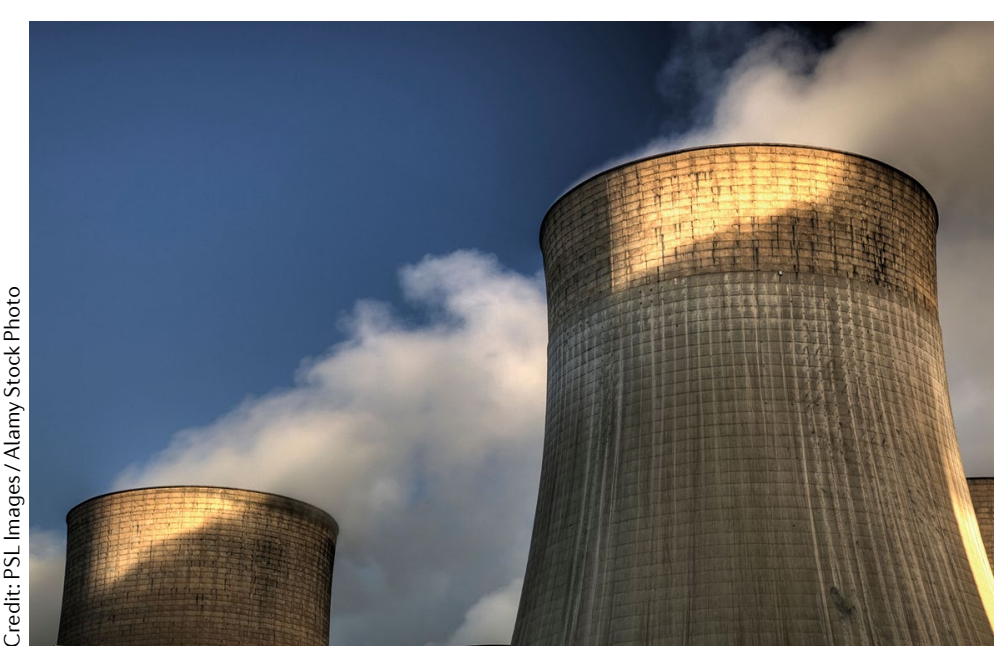

co-authors, use a combination of energy, activity and policy data to estimate the changes in daily $\mathrm{CO}_{2}$ emissions arising from COVID-19-related confinement impacts on six economic sectors: power, surface transport, industry, aviation, residential buildings, and public buildings and commerce. Compared with 2019, global daily emissions in early April decreased by $17 \%$ (depending on assumptions, $11 \%$ to $25 \%$ ), reflecting a reduction of $17 \mathrm{MtCO}_{2}$ per day

(11-25 $\mathrm{MtCO}_{2}$ per day), nearly half of which $\left(43 \%\right.$, or $5.9-9.6 \mathrm{MtCO}_{2}$ per day) can be attributed to changes in the surface transport sector. The largest relative declines, however, were observed in the aviation industry sector $(60 \%$, or 1.3-2.2 $\mathrm{MtCO}_{2}$ per day). Up until the end of April 2020, these changes reflect total global decreases of 1,048 $\mathrm{Mt} \mathrm{CO}_{2}$ (543-1,638), which, depending on when lockdown measures ease, could reach 2,729 $\mathrm{MtCO}_{2}$ (986-4,717).

While these $\mathrm{CO}_{2}$ reductions represent environmental benefits, the total 'savings' are consistent with those needed year-on-year to reach the goals of the Paris Agreement. Thus, the extreme measures during the COVID-19 pandemic also act to highlight the fundamental changes needed to constrain impacts from anthropogenic climate change. Moreover, post-crisis rebounds in emissions may counter or restore emissions along original trajectories, demonstrating the influence of political and economic stimuli in dictating emissions trajectories well beyond 2020 .

Graham Simpkins

ORIGINAL ARTICLE Le Quéré, C. et al. Temporary reduction in daily global $\mathrm{CO}_{2}$ emissions during the COVID-19 forced confinement. Nat. Clim. Change https://doi.org/10.1038/s41558-020-0797-x (2020) 